\title{
Pollination of Cucurbita spp. (Squash and Pumpkin) Crops in Florida ${ }^{1}$
}

\author{
Rachel E. Mallinger and Oscar E. Liburd ${ }^{2}$
}

\section{Introduction}

Squash and pumpkin (Cucurbita spp.) are economically significant crops in Florida with over 7,900 acres in production and an estimated value of $\$ 35,412,000$ (USDA NASS 2019). All varieties of squash and pumpkin are highly dependent on insect pollination, without which crop yields are low to nonexistent. In Florida, there are two distinct growing seasons for squash and pumpkin: spring and fall. Summer squash is generally grown during the late spring and early fall, and common varieties include crookneck, cash flow, gold rush, Zephyr, and black beauty. Acorn, butternut, Seminole, and spaghetti are typically referred to as winter squash and are grown in late fall and early spring. Regardless of when the crop is grown, successful pollination is an important step in the production of squash and pumpkins. This publication describes the pollination biology and requirements of Cucurbita spp., signs and causes of poor pollination, and recommendations for improving pollination of these crops in Florida.

\section{Flower Structure and Pollination Requirements}

Cucurbita spp. plants produce large, bell-shaped, yelloworange flowers along low-lying vines or bushes (Figure 1). Plants are typically monoecious and have imperfect flowers, meaning they produce separate, individual male or female flowers on the same plant. Female flowers are the only ones that develop into squash or pumpkins following successful pollination and fertilization and can be identified by the stigma in the center of the flower (Figure 1) and by a wider flower stem that resembles a small, immature fruit. Male flowers produce pollen to fertilize female stigmas and can be identified by the anther in the center of the flower (Figure 1) and by a narrower flower stem. When open and receptive, female stigmas have a multifaceted shape with multiple sticky, shiny "knobs" while male anthers are simpler in shape with a single projection and appear dusty when releasing pollen (Figure 1). While all species and varieties typically produce numerous flowers over a bloom period of several weeks, individual flowers are only open for a few hours in the morning, typically lasting until around noon (Tepedino 1981; Cane et al. 2011; Campbell et al. 2013). Thus, the pollination window for an individual flower is short.

The ratio of male to female flowers produced by plants can vary across varieties and with environmental factors such as day length, temperature, and precipitation (NeSmith et al. 1994; Campbell et al. 2013). This ratio can affect pollination success because both male and female flowers need to be open at the same time and in the same area to ensure successful pollen transfer. Additionally, the total number of female flowers produced by a plant can vary across plants and with environmental factors, thereby influencing crop yields.

1. This document is ENY-2056, one of a series of the Entomology and Nematology Department, UF/IFAS Extension. Original publication date February 2021. Visit the EDIS website at https://edis.ifas.ufl.edu for the currently supported version of this publication.

2. Rachel E. Mallinger, assistant professor; and Oscar E. Liburd, professor, Entomology and Nematology Department; UF/IFAS Extension, Gainesville, FL 32611.

The Institute of Food and Agricultural Sciences (IFAS) is an Equal Opportunity Institution authorized to provide research, educational information and other services

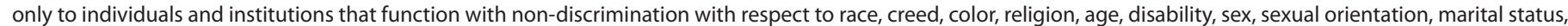

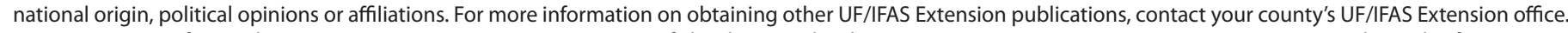
U.S. Department of Agriculture, UF/IFAS Extension Service, University of Florida, IFAS, Florida A \& M University Cooperative Extension Program, and Boards of County Commissioners Cooperating. Nick T. Place, dean for UF/IFAS Extension. 


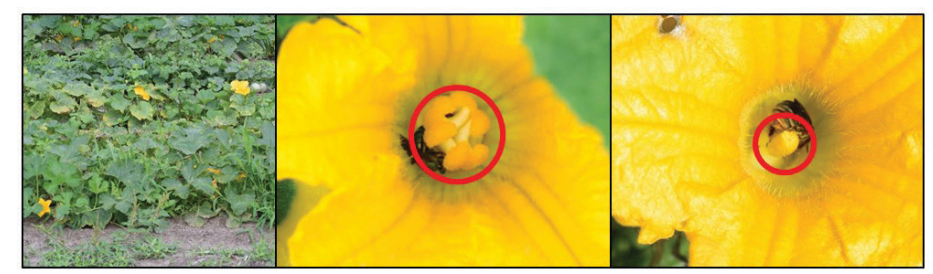

Figure 1. A squash field in bloom (left), a female flower (center), and a male flower (right). Flower reproductive organs that can be used to sex flowers are circled in red.

Credits: Rachel Mallinger, UF/IFAS

\section{Pollinators of Squash and Pumpkin}

Cucurbita spp. have relatively heavy pollen and deep flowers, which means that wind is not an adequate pollinator for squash. Bees are the most frequent and effective pollinators, though other insects such as ants, beetles, and flies may contribute to pollination. Depending on the pollinator, multiple visits are required to deposit enough pollen to set optimal fruit. For example, five visits by male squash bees, Peponapis pruinosa, resulted in significantly bigger fruit compared to a single visit (Cane et al. 2011), and open flowers receiving multiple pollinator visits set bigger fruit than those receiving only single visits by either honey bees, Apis mellifera, or squash bees (Tepedino 1981).

\section{Wild Pollinators}

Cucurbita spp. are native to North America and thus share a long evolutionary history with a suite of native wild bees. In particular, native bees in the genera Peponapis and Xenoglossa specialize on pollen and nectar provided by Cucurbita spp. flowers. As specialists, they are constant and faithful visitors to squash and pumpkin flowers and are effective pollinators (Adler and Hazzard 2009; Hladun and Adler 2009). In addition, generalist native bees including sweat bees (Halictidae) and bumble bees (Bombus spp.) visit and pollinate squash and pumpkin (Shuler at al. 2005; Adler and Hazzard 200; Hladun and Adler 2009; Julier and Roulston 2009).

Wild squash and pumpkin pollinators in Florida differ from those in much of North America, however. While the specialist squash bees Peponapis spp. are some of the most frequent and effective pollinators of squash elsewhere in North America, they are not found in Florida (Tepedino 1981; Canto-Aguilar and Parra-Tabla 2000; Shuler et al. 2005; Julier and Roulston 2009). Other squash specialist bees Xenoglossa spp. are found in Florida, but they are limited to the northern region of the state and have foraging periods that only overlap with a spring blooming crop (Figure 2; Hall et al. 2010). Xenoglossa spp. were not found visiting squash in northern Florida during a fall bloom, although they have been found in abundance on flowers during the spring bloom (Table 1; Figure 2). Sweat bees, however, were common visitors to squash blossoms in Florida during the fall (Table 1; Figure 2). Foraging periods for many sweat bees as well as bumble bees are long and span both a spring and fall bloom. Thus, though squash bees, Xenoglossa spp., pollinate the crop only in the spring, sweat bees and bumble bees are potential pollinators for both a spring and fall crop in Florida.

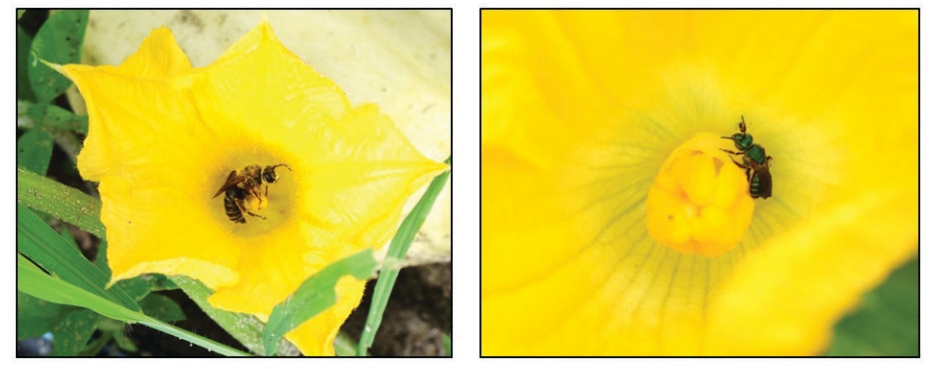

Figure 2. A male squash bee (Xenoglossa spp.) (left) and a female sweat bee (Halictidae) (right) visiting squash flowers. Photographs were taken on a farm near Gainesville, Florida, in spring 2018.

Credits: Rachel Mallinger, UF/IFAS

\section{Managed Honey Bees}

Along with a community of native, wild pollinators, managed honey bees (Apis mellifera) are often used for pollination in commercial squash and pumpkin fields. In comparison to the squash specialist Peponapis limitarsis, honey bees made fewer visits to squash flowers and deposited four times less pollen per visit (Canto-Aguilar and Parra-Tabla 2000). However, in relation to another squash specialist, Peponapis pruinosa, they were equally effective pollinators (Tepedino 1981). On some squash and pumpkin farms, the addition of managed honey bees did not improve yields, likely because ample native wild bees were already present to pollinate the crop (Shuler et al. 2005).

Certain behaviors of honey bees can compromise their efficacy as pollinators. For instance, honey bees may not show a strong affinity for squash flowers, instead preferring to visit other flowers (Shuler et al. 2005). Secondly, when honey bees do visit Cucurbita spp. flowers, they typically show a strong preference for female flowers and do not as frequently collect pollen compared to other native bees (Tepedino 1981; Table 1). However, bees that prefer male flowers and infrequently visit female flowers, such as sweat bees observed in Florida, may also be relatively ineffective pollinators (Table 1). More research is needed to determine how bee preferences for male and female flowers affect their pollination value. Regardless, honey bees may still be useful pollinators due to their sheer numbers, particularly in areas where wild pollinators are scarce. For example, in northern 
Florida during a fall bloom, honey bees were the dominant visitors to squash flowers (Table 1 ).

\section{Managed Bumble Bees}

Adding commercially available bumble bee colonies

(Bombus impatiens) may significantly improve yields (Artz and Nault 2011). Bumble bees can be purchased from two North American companies (Biobest Canada Ltd., Leamington, ON and Koppert Biological Systems Inc., Howell, MI) in field-ready quads consisting of four colonies each. The commercially available species, Bombus impatiens, is native to Florida, and showed high attraction to Cucurbita spp. flowers in other parts of the southeastern United States (Julier and Roulston 2009). Bumble bee colonies only live for one year and thus need to be restocked for pollination each growing season.

\section{Signs and Causes of Poor Pollination}

\section{Signs}

Pollination problems can be identified by low fruit set and/ or small, misshapen fruit. It is important to differentiate between male and female flowers and assess fruit set as the proportion of female flowers setting fruit because only the female flowers have the potential to set fruit. Fruit set can be determined by counting the number of developing fruit relative to the number of female flowers after the bloom period (e.g., 10 female flowers in a crop row resulting in 4 marketable fruit in that row $=40 \%$ fruit set).

\section{Causes}

Pollination problems can be the result of limited pollinator activity on crop flowers. Limited pollinator activity can occur if few pollinators are present in the field but can also occur even when pollinators are abundant if: (1) pollinators are visiting other competing flowers on or near the farm; and/or (2) weather is not conducive to pollinator activity. Extreme weather, including very high or low temperatures, high humidity, fog, or continuous precipitation can reduce pollinator visitation to flowers (Dorjay et al. 2017).

In addition to pollinator activity, pollination success is dependent on flower sex ratio and physiology. If ratios of male to female flowers in a field are highly skewed in either direction, pollination and fruit set can be reduced (Campbell et al. 2013). For example, observations on a farm near Gainesville, Florida, showed high variability in the proportion of female flowers across three varieties and over the bloom period, including times when certain varieties were producing nearly all female or all male flowers (Figure 3). Many plants will produce predominately male flowers at the beginning of bloom and predominately female flowers towards the end of bloom, but there is variation in this pattern across varieties (Figure 3 ). The total number of female flowers produced by these same plants also varied across varieties (Figure 3) and can be a factor influencing overall yields. Finally, pollination is dependent on the quality of pollen available for fertilization. Extreme weather, including high temperatures and high humidity, may reduce pollen viability and therefore pollination success (Herrero and Johnson 1980).

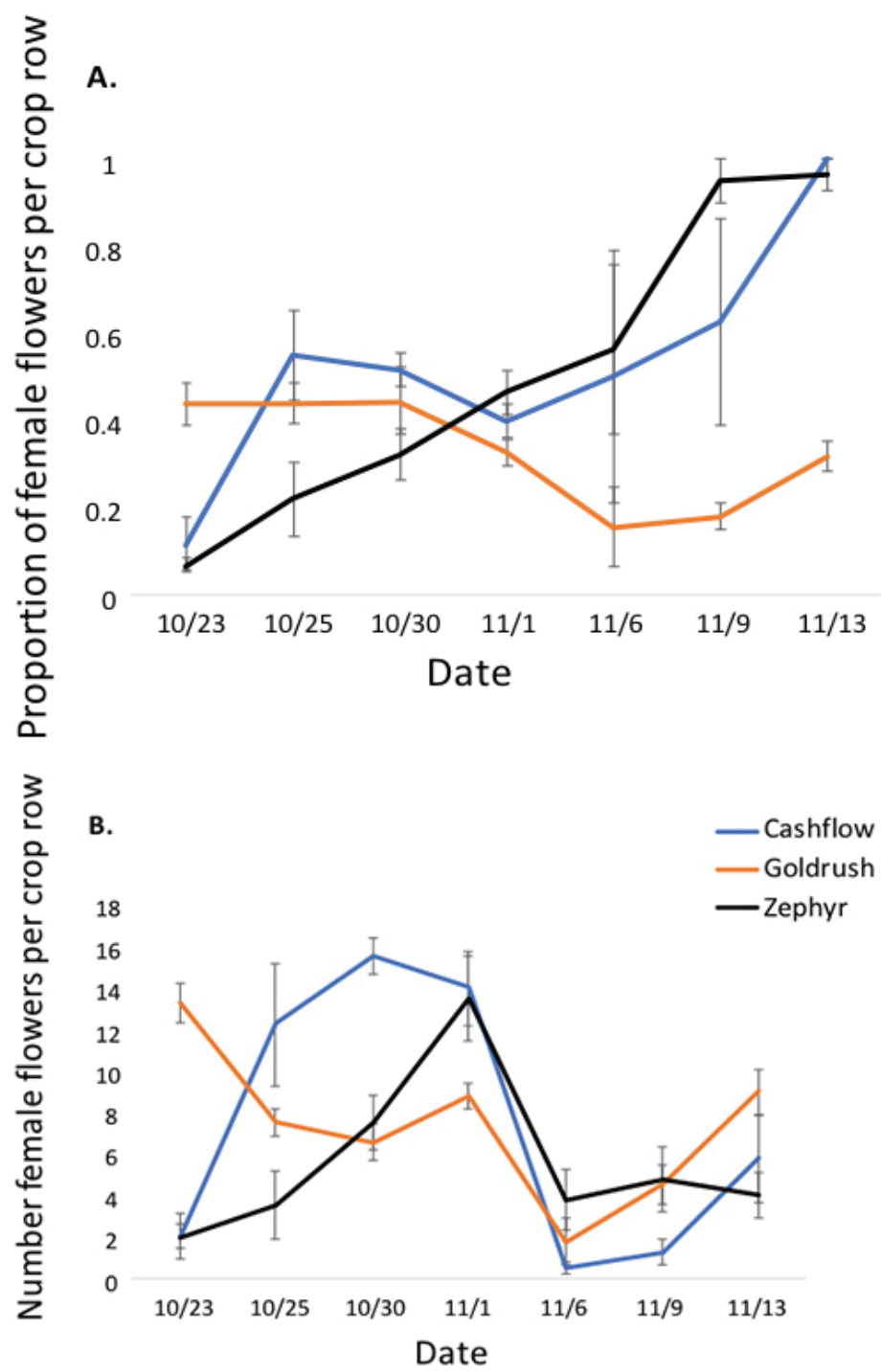

Figure 3. The proportion of female flowers within a crop row across three different summer squash varieties grown in fall 2018 (top) and the number of female flowers per crop row for these same varieties (bottom). Squash was grown at a farm near Gainesville, Florida, with organic management.

\section{Improving Pollination}

Pollination for squash and pumpkins in Florida can be improved by adding managed bees, increasing wild bee 
populations, or employing certain horticultural practices that assist pollination.

\section{Managed Bees}

Managed honey bees can be added to the farm during bloom at a typical density of 1-2 hives per acre. Honey bee rental costs can vary considerably but are generally in the range of $\$ 40-\$ 100$ per hive per bloom period. While previous studies outside of Florida suggest that adding honey bees does not always result in increased pollination and yields (Shuler et al. 2005; Walters and Taylor 2006), they may be particularly useful when there are few wild pollinators available. Along with honey bees, growers could consider the addition of managed bumble bees. Bumble bees have been shown to be effective pollinators, even more so than honey bees, and pumpkin fields stocked with managed bumble bees had greater yields than those without managed bumble bees (Artz and Nault 2011; Julier and Roulston 2009). However, there are few guidelines for bumble bee colony density and placement in Cucurbita spp. crops. Growers in other crops typically use a recommended 1 quad per acre at a cost of app. $\$ 300$ per quad.

\section{Attracting and Increasing Wild Pollinators}

Growers may be able to enhance wild pollinator populations in and around their farms by planting supplemental floral resources. Flower strips have increased pollinator activity and crop yields in other agroecosystems (Blauuw and Isaacs 2014; Venturini et al. 2017; Giffiths-Lee et al. 2020). Bumble bees and many sweat bees that contribute to Cucurbita spp. pollination are generalists with nearly year-round forage activity, requiring floral resources throughout most of the year. Wildflowers, other flowering crops, or even flowering weeds in and around the farm can provide floral resources for these bees outside of squash bloom. Ideally, flower strips will provide floral resources for pollinators when the target crop (squash and pumpkin) is not blooming but minimize competition during target crop bloom. In Florida, this would mean providing flowers in the summer from June-September. Numerous resources exist to guide farmers in planting floral resources for bees, including the UF/IFAS publication A Guide to Planting Wildflower Enhancements in Florida (https://edis.ifas.ufl. edu/in1180).

Many squash and pumpkin pollinators, including the squash specialists, such as Xenoglossa spp., nest belowground and require suitable nesting habitat consisting of relatively bare, sun-exposed soil. Significant ground disturbance through tilling or other practices can reduce bee emergence and abundance (Ullmann et al. 2016), though tilling does not necessarily destroy bee nests (Julier and Roulston 2009; Ullmann et al. 2016). The presence of relatively bare ground that is not frequently tilled in the area around the crop could therefore encourage and support ground-nesting bees.

Finally, minimizing pesticide exposure can help to maintain abundant and diverse pollinator communities (Tuell and Isaacs 2010; Chan et al. 2012; Stoner and Eitzer 2012; Mallinger et al. 2015). Bees may be exposed to pesticides through interactions with treated flowers as well as through direct contact to treated nest materials including soil or contaminated water. For generalist bees with long foraging periods, such as bumble bees and some sweat bees, exposure to pesticides can occur both during and outside of the Cucurbita spp. growing season. Guidelines to reduce bee exposure to pesticides include the following:

1. Avoid treating crops when they are blooming and remove flowering weeds from the treatment area before applying pesticides.

2. Spray late in the day or at night, especially if applying pesticides to plants in bloom.

3. Select pesticides with a low toxicity to bees especially if applying pesticides to plants in bloom (Stoner and Eitzer 2012). Note: When possible, avoid using systemic pesticides including neonicotinoids because these chemicals can be found in squash pollen and nectar as well as in the soil where bees nest (Chan et al. 2012).

4. Triple-rinse spraying equipment with water after application to prevent unintended contamination of pesticide mixtures with previous pesticides used.

\section{Horticultural Practices}

To ensure successful pollination, both male and female flowers need to be open on the same day within the same general area. Therefore, the ratio of male to female flowers can influence pollination. Because some varieties produce skewed ratios of male to female flowers during periods of bloom (Figure 3), planting multiple varieties within the same field could help to ensure the presence of both sexes for pollination. However, squash and pumpkins do not require cross-pollination between varieties for successful fruit set. Additionally, increasing the number of female flowers produced by plants can increase overall yields provided that there are still adequate numbers of male flowers to pollinate. Female flower production may be enhanced by treating plants with hormones and growth regulators including auxin and ethephon as well as by soaking seeds 
in garlic extract prior to planting (Glala et al. 2012; Mancini and Calabrese 1999). However, very high female-to-male sex ratios can reduce pollination rates and subsequent yields (Campbell et al. 2013), so the goal should be to maintain some male flower production. Finally, while bee attractants have been developed to increase bee visitation, studies in related crops (watermelon and cucumber) found them to be ineffective in increasing pollinator visits and/or yields (Schultheis et al. 1994; Ellis and Delaplane 2009).

\section{Summary}

Squash and pumpkins are highly dependent on bee pollinators for adequate yields. In Florida, managed honey bees, managed and wild bumble bees, and sweat bees provide pollination for both a spring and fall bloom, while the highly effective squash bees pollinate the spring crop. If signs of poor pollination are present (low fruit set and/or small and misshapen fruit), consider adding or increasing densities of managed bees (honey bees and bumble bees), evaluating female-to-male flower ratios throughout bloom, planting multiple varieties in the same field, and supporting abundant wild bees through supplemental floral resources and pesticide stewardship.

\section{References Cited}

Adler, L. S., and R. V. Hazzard. 2009. "Comparison of Perimeter Trap Crop Varieties: Effects on Herbivory, Pollination, and Yield in Butternut Squash." Environ. Entomol. 38:207-215. https://doi.org/10.1603/022.038.0126

Artz, D. R., and B. A. Nault. 2011. "Performance of Apis mellifera, Bombus impatiens, and Peponapis pruinosa (Hymenoptera: Apidae) as Pollinators of Pumpkin." J. Econ. Entomol. 104:1153-1161.

Blaauw, B. R., and R. Isaacs. 2014. "Flower Plantings Increase Wild Bee Abundance and the Pollination Services Provided to a Pollination-Dependent Crop." J. Appl. Ecol. 51:890-898. https://doi.org/10.1111/1365-2664.12257

Campbell, L. G., J. Luo, and K. L. Mercer. 2013. "Effect of Water Availability and Genetic Diversity on Flowering Phenology, Synchrony and Reproductive Investment in Summer Squash." The Journal of Agricultural Science 151:775-786. https://doi.org/10.1017/S0021859612000731

Cane, J. H., B. J. Sampson, and S. A. Miller. 2011. "Pollination Value of Male Bees: The Specialist Bee Peponapis pruinosa (Apidae) at Summer Squash (Cucurbita pepo)." Environmental Entomology 40:614-620. https://doi. org/10.1603/EN10084
Canto-Aguilar, M. A., and V. Parra-Tabla. 2000.

"Importance of Conserving Alternative Pollinators: Assessing the Pollination Efficiency of the Squash Bee, Peponapis limitaris in Cucurbita moschata (Cucurbitaceae)." Journal of Insect Conservation 4:201-208. https://doi. org/10.1023/A:1009685422587

Chan, D. S. W., R. S. Prosser, J. L. Rodríguez-Gil, and N. E. Raine. 2019. "Assessment of Risk to Hoary Squash Bees (Peponapis pruinosa) and Other Ground-Nesting Bees from Systemic Insecticides in Agricultural Soil." Sci. Rep. 9:11870. https://doi.org/10.1038/s41598-019-47805-1

Dorjay, N., D. P. Abrol, and U. Shankar. 2017. "Insect Visitors on Cucumber and Bittergourd Flowers and Impact on Quantity of Crop Production by Different Pollination Treatment." Journal of Apiculture 32:77-88.

Ellis, A., and K. S. Delaplane. 2009. "An Evaluation of FruitBoost (TM) as an Aid for Honey Bee Pollination under Conditions of Competing Bloom.” J. Apic. Res. 48:15-18. https://doi.org/10.3896/IBRA.1.48.1.04

Glala, A. A. A., E. E. H. Abd El-Samad, S. O. El-Abd, and H. A. Obiadalla-Ali. 2012. "Increasing Organic Production of Summer Squash by Modulating Plant Sex Ratio." Acta Hortic. 933:137-143. https://doi.org/10.17660/ ActaHortic.2012.933.15

Griffiths-Lee, J., E. Nicholls, and D. Goulson. 2020. "Companion Planting to Attract Pollinators Increases the Yield and Quality of Strawberry Fruit in Gardens and Allotments." Ecological Entomology 45 (5): 1025-1034. https:// doi.org/10.1111/een. 12880

Hall, H. G. 2010. “The Squash Bee Xenoglossa kansensis Cockerell (Hymenoptera: Apidae) Found in Organic Farms in Northern Florida." Journal of the Kansas Entomological Society 83:84-88.

Herrero, M. P., and R. R. Johnson. 1980. "High Temperature Stress and Pollen Viability of Maize1.” Crop Science 20:796. https://doi.org/10.2135/cropsci1980.0011183X0020000600 $30 \mathrm{x}$

Hladun, K. R., and L. S. Adler. 2009. "Influence of Leaf Herbivory, Root Herbivory, and Pollination on Plant Performance in Cucurbita moschata." Ecological Entomology 34:144-152. https://doi.org/10.1111/j.1365-2311.2008.01060.x 
Julier, H. E., and T. H. Roulston. 2009. "Wild Bee Abundance and Pollination Service in Cultivated Pumpkins: Farm Management, Nesting Behavior and Landscape Effects." Journal of Economic Entomology 102:563-573. https://doi.org/10.1603/029.102.0214

Mallinger, R. E., P. Werts, and C. Gratton. 2015. "Pesticide Use within a Pollinator-Dependent Crop Has Negative Effects on the Abundance and Species Richness of Sweat Bees, Lasioglossum spp., and on Bumble Bee Colony Growth." Journal of Insect Conservation 19:999-1010. https://doi. org/10.1007/s10841-015-9816-Z

Mancini, L., and N. Calabrese. 1999. "Effect of Growth Regulators on Flower Differentiation and Yield in Zucchini (Cucurbita pepo L.) Grown in Protected Cultivation." Acta Hortic. 492:265-272. https://doi.org/10.17660/ actahortic.1999.492.35

NeSmith, D. S., G. Hoogenboom, and D. W. Groff. 1994. "Staminate and Pistillate Flower Production of Summer Squash in Response to Planting Date." HortScience 29:256-257. https://doi.org/10.21273/HORTSCI.29.4.256

Schultheis, J. R., J. T. Ambrose, S. B. Bambara, and W. A. Mangum. 1994. "Selective Bee Attractants Did not Improve Cucumber and Watermelon Yield." HortScience 29:155-158.

Shuler, R., T. Roulston, and G. Farris. 2005. "Farming Practices Influence Wild Pollinator Populations on Squash and Pumpkin." Journal of Economic Entomology 98:790-795.

Stoner, K. A., and B. D. Eitzer. 2012. "Movement of SoilApplied Imidacloprid and Thiamethoxam into Nectar and Pollen of Squash (Cucurbita pepo)." PLOS ONE 7:e39114. https://doi.org/10.1371/journal.pone.0039114

Tepedino, V. J. 1981. “The Pollination Efficiency of the Squash Bee (Peponapis pruinosa) and the Honey Bee (Apis mellifera) on Summer Squash (Cucurbita pepo)." Journal of the Kansas Entomological Society 54:359-377.

Tuell, J. K., and R. Isaacs. 2010. "Community and SpeciesSpecific Responses of Wild Bees to Insect Pest Control Programs Applied to a Pollinator-Dependent Crop." J. Econ. Entomol. 103:668-675.

Ullmann, K. S., M. H. Meisner, and N. M. Williams. 2016. "Impact of Tillage on the Crop Pollinating, Ground-Nesting Bee Peponapis pruinosa in California." Agriculture, Ecosystems \& Environment 232:240-246. https://doi.org/10.1016/j. agee.2016.08.002
Venturini, E. M., F. A. Drummond, A. K. Hoshide, A. C. Dibble, and L. B. Stack. 2017. "Pollination Reservoirs for Wild Bee Habitat Enhancement in Cropping Systems: A Review." Agroecology and Sustainable Food Systems 41:101-142. https://doi.org/10.1080/21683565.2016.12583 77

Walters, S. A., and B. H. Taylor. 2006. "Effects of Honey Bee Pollination on Pumpkin Fruit and Seed Yield." HortScience 41:370-373. https://doi.org/10.21273/HORTSCI.41.2.370 
Table 1. Flower visitors to summer squash during fall 2018 on a farm near Gainesville, Florida. Observations recorded include the percentage of visits made by each pollinator group, the proportion of visitors within each group that were found on male vs. female flowers, and the proportion of visitors collecting pollen.

\begin{tabular}{|l|c|c|c|c|}
\hline \multicolumn{1}{|c|}{ Pollinator } & $\begin{array}{c}\text { Percentage of total } \\
\text { pollinator visits }\end{array}$ & $\begin{array}{c}\text { Proportion visits by } \\
\text { each group to male } \\
\text { flowers }\end{array}$ & $\begin{array}{c}\text { Proportion visits by } \\
\text { each group to female } \\
\text { flowers }\end{array}$ & $\begin{array}{c}\text { Proportion visitors } \\
\text { collecting pollen }\end{array}$ \\
\hline Honey bee (Apis mellifera) & $82 \%$ & 0.22 & 0.78 \\
\hline $\begin{array}{l}\text { Green sweat bees (Agapostemon, } \\
\text { Augochlora, Augochloropsis, and } \\
\text { Augochlorella spp.) }\end{array}$ & $14.5 \%$ & 0.75 & 0.25 \\
\hline Other bees & & & 0.09 \\
\hline
\end{tabular}

